\title{
Graduate studies on optoelectronics in Argentina: an experience
}

Juan Fernández, María Garea, Silvia Isaurralde, Liliana Perez, Carlos Raffo

Juan C. Fernández, María T. Garea, Silvia Isaurralde, Liliana I. Perez, Carlos A. Raffo, "Graduate studies on optoelectronics in Argentina: an experience," Proc. SPIE 9289, 12th Education and Training in Optics and Photonics Conference, 92890X (17 July 2014); doi: 10.1117/12.2070743

SPIE Event: 12th Education and Training in Optics and Photonics Conference, 2013, Porto, Portugal 


\title{
Graduate Studies on Optoelectronics in Argentina: An experience
}

\author{
Juan C. Fernández, María T. Garea, Silvia Isaurralde, Liliana I. Perez, Carlos A. Raffo \\ Posgrado en Ingeniería Optoelectrónica, \\ Facultad de Ingeniería, Universidad de Buenos Aires, \\ Paseo Colón 850, Ciudad de Buenos Aires, C1063ACV, Argentina
}

\begin{abstract}
The number of graduate programs in Optoelectronics in Argentina is scarce. The current Optics and Photonics Education Directory lists only three programs. One of them was launched in 2001 in the Facultad de Ingeniería (College of Engineering), Universidad de Buenos Aires (UBA). This was the first graduate program in the field, leading to a Master Degree in Optoelectronics. This decision arose from the demand of telecommunications industries and several estate- or private-funded research institutions working with us in the fields of lasers, optics, remote sensing, etc. A great bonus was the steady work, during several decades, of research groups in the College on the development of different type of lasers and optical non destructive tests and their engineering applications.

As happened in many engineering graduate programs in Argentina at that time, few non full-time students could finish their studies, which called for 800 hours of traditional lecture-recitation classes, and the Master Thesis.

In recent years Argentine Education authorities downsized the Master programs to 700 hours of blended learning and we redesigned the Graduate Optoelectronic Engineering Program to meet the challenge, dividing it in two successive one year programs, the first aimed at a professional training for almost immediate insertion in the labor market (called Especialización en Ingeniería Optoelectrónica), and the second (called Maestría en Ingeniería Optoelectrónica y Fotónica) aimed at a more academic and research target to comply with the UBA standards for Master degrees.

The present work is a presentation of the new program design, which has begun in the current year.
\end{abstract}

Keywords: Optoelectronics Education, Master Programs, Graduate Engineering Programs, Latin America

\section{INTRODUCTION}

To adequately frame at present an Optoelectronics and Photonic Engineering Graduate Study Program, it is convenient to cite the scope defined by one of the leading periodicals in the field of optoelectronics: IET Optoelectronics, published by the Institution of Engineering and Technology (IET-Britain): ${ }^{1}$

"IET Optoelectronics covers but is not limited to the following topics: Optical and optoelectronic materials; Light sources, including LEDs, lasers and devices for lighting; Optical modulation and multiplexing; Optical fibres, cables and connectors; Optical amplifiers; Photodetectors and optical receivers; Photonic integrated circuits; Nanophotonics and photonic crystals; Optical signal processing; Holography; Displays."

In the same fashion, one of the leading periodicals in the field of photonics, IEEE Photonics, published by the Institute of Electric and Electronic Engineers (IEEE-USA) defines its target: ${ }^{2}$

"IEEE Photonics is an online-only rapid publication archival journal of top quality research at the fore-front of Photonics. Photonics integrates quantum electronics and optics to accelerate progress in the generation of novel photon sources and in their utilization in emerging applications at the micro and nano scales spanning from the far-infrared/THz to the $\mathrm{x}$-ray region of the electromagnetic spectrum. Original short and full length contributions to IEEE Photonics are welcome. Contributions can address issues ranging from fundamental understanding to emerging technologies and applications. "

From these viewpoints, engineering undergraduate studies about these disciplines in Argentina is very limited and only offered at an informative level. This happens in the College of Engineering, University of Buenos Aires (Facultad de Ingeniería, Universidad de Buenos Aires - FI UBA) as well as in other university centers.

12th Education and Training in Optics and Photonics Conference, edited by

Manuel F. P. C. Martins Costa, Mourad Zghal, Proc. of SPIE Vol. 9289, 92890X

(C) 2014 SPIE, OSA, IEEE, ICO · doi: 10.1117/12.2070743 
Graduate study programs do not offer much more. According with the Optics and Photonics Education Directory ${ }^{3}$ maintained by the Society of Photographic Instrumentation Engineers (SPIE), in Argentina there are only three Graduate Programs linked with optics and photonics: the Master Degree in Optoelectronics and Photonics Engineering (FI UBA), a Ph.D. Physics program in optical metrology in the National University of Rosario and a graduate program on Lighting and Vision in the National University of Tucuman. Only the Buenos Aires program covers most fields in optoelectronics engineering.

In 2001, arising from the human and lab resources developed over fifty years in FI UBA in research and development on optics, lasers, image processing and many engineering applications, the first Master degree program in Optoelectronics was created.

This program was designed with a two years schedule with a total of 800 hours of lecture-recitation and lab classes, apart from the defense of a Master Thesis. These were hard requisites for (many) working professionals who enrolled as students, and who could not complete the course work or, having completed it, were not able to find the time and make the effort to write the thesis.

Aware of these setbacks the FI UBA authorities decided in 2011 to reshape the optoelectronics graduate program reducing the schedule and mixing lecture-recitation classes, blended learning and virtual learning using the web resources now widely available, and introducing a follow-up program for thesis writing to help the student in his research and writing work. Also, the new program is more flexible than the former, including elective studies to follow the technological trends, the research lines in College and associated research groups, the opportunity of getting credits from short or long courses presented by visiting researchers, etc.

To date the FI UBA has six research groups with over forty people working in associated optoelectronic fields and actively present in the Graduate Program: Applied Optics Lab (Laboratorio de Aplicaciones Ópticas), Optoelectronics Lab (Laboratorio de Optoelectrónica), Laser Lab (Laboratorio de Láser), Optics and Vision Group (Grupo de Óptica y Visión), Signal Processing and Communications Group (Grupo de Procesamiento de Señales y Comunicaciones), and the Signal and Image Processing Research with Neural Networks Lab (Laboratorio de Investigación en Procesamiento de Señales e Imágenes y Redes Neuronales), belonging to the Departaments of Physics and Electronics. These groups provide teachers, research lines, lab, computing and expertise resources and plenty of good advice to students in the graduate program.

There are many applications of optoelectronics and photonics in the local state facilities and private enterprises, which use foreign equipment and know-how, for there are few and only incipient local developments. There are usual applications in communications, laser machining and shaping of metals, thermography, remote sensing, aerial and satellite imagery, non destructive essays on materials, biomedical and biochemical equipment and tests, defense and security applications, surveying and urban planning, environmental studies and remediation, natural resources assessment and control, among others. This state of affairs guarantees good job opportunities to graduates of the program and a more efficient expenditure in research, development and maintenance for local companies.

The FI UBA Optoelectronics program offers a one-year Specialty Title: Especialista en Ingeniería Optoelectrónica. This is a professional-oriented program for fast insertion in the work market. The studies end with a Graduate Thesis on an engineering Project in the field. Those interested in development and research can continue with a second year to achieve a Master Title: Magister en Ingeniería Optoelectrónica y Fotónica. This second year ends with a Master Thesis.

In this work we present a scheme of these two new graduate programs, their contents and aims.

\section{OPTOELECTRONICS PROGRAMS DETAILS}

The Engineering Optoelectronics Graduate Studies Program include a first year of a professional-oriented currículum aimed to engineers already working in the field or those who intend to enter in the field but have not the necessary expertise. This cycle ends with a Graduate Thesis work directed by one of the professors or a specialist on the subject and it is defended in front a committee of three specialists not belonging to the Program faculty. The student who has passed these instances receives the title of Especialista en Ingeniería Optoelectrónica de la Universidad de Buenos Aires. 
The student can choose not to make this Graduate Thesis but to remain for a second year of study on a more academical and research oriented curriculum. This stage ends with the development of a Master Thesis work, again directed by one of the professors or a specialist on the subject and defended in front a committee of three specialists not belonging to the Program faculty. In this case the student receives the title of Magister en Ingeniería Optoelectrónica y Fotónica de la Universidad de Buenos Aires.

The first cycle (Specialty cycle and/or first year of Master cycle - one year) include the following subjects (the number of hours of each subject includes lecture-recitation classes, lab work and blended learning activities):

\section{Complementary Studies (75 hs.)}

Complements of Mathematics

Linear systems. Spatial Fourier transform. Wavelets. Special functions and numerical methods for optoelectronics systems.

Complements of Optics and Optics Laboratory

Optical systems. Geometrical optics. Matrix models. Wave optics. The students will perform basic lab experiences to acquaint them with optical systems.

\section{Basic Technologies (145 hs.)}

Radiation Sources

Natural and artificial radiation sources. Lasers. Basic theory and examples of laser systems in optoelectronics.

Detectors and Detection Systems

Thermal and quantum detectors. Detector arrays. Detection systems for optoelectronics. Characterization and calibration.

Free and guided radiation propagation

Free electromagnetic wave propagation. Atmospheric and ionospheric transmission. Guided propagation and transmission. Dielectric guides and optical fibres. Characterization, uses and construction.

Optoelectronics Laboratory

The students will perform basic lab experiences of emission, transmission and detection of optical and optoelectronic signals.

\section{Applied Technologies(90 hs.)}

Optical Communications

Optical communication systems. Optical emitters, transmitters and receptors. Basic structure of a commercial optical communications systems. Standards and regulations.

Commercial and Industrial Applications I

Diverse applications of optical and mixed optoelectronical emitter and receiver systems, in particular lasers and leds,

Commercial and Industrial Applications II

Applications of optical and optoelectronical systems in medicine, industry and vision systems in defense, surveillance and security.

\section{Graduate Thesis Work (58 hs.)}

In this first cycle the studies conclude with a Graduate Thesis work with a professional aim that reflects some industrial or commercial need related to optoelectronics engineering. The student has to attend a mandatory Seminar on 
Methodology of Technological Research and optional workshops on Thesis design and writing, and other subjects related to the student's particular Thesis field.

The work is directed by one professor of the faculty or an external specialist, and must be defended in front of a committee of three specialists not in the Program faculty. After completing the courses and a successful defense of the Thesis, the student receives the title of Especialista en Ingeniería Optoelectrónica de la Universidad de Buenos Aires

It is expected that this work may be presented in a regional or international professional meeting on the field.

At this stage the student may choose not to complete the Graduate Thesis work for the title of Especialista and follow the second year cycle to complete the Master studies. Also, the student may finish the Especialista title and follow into the next year for the Master title.

The second cycle (Master cycle - one year) includes the following subjects (the number of hours of each subject consists of lecture-recitation classes, lab work and blended learning activities):

\section{Advanced Topics (110 hs.)}

Advanced Topics on Laser and Laser Laboratory

Theoretical and lab advanced topics in laser, including (but not limited to) description and characterization of gaseous, líquid, solid, semiconductor, atomic and molecular lasers. The student will perform lab experiences with different types of commercial, industrial and research lasers and will learn on measuring and assessment methods.

Advanced Topics on Optics of Materials

Topics including (but are not limited to) propagation, reflection, transmission, absorption, emission, dispersion and scattering of electromagnetic waves in linear, non-linear, isotropic, anisotropic, homogeneous, non-homogeneous, chiral and active material media.

Advanced Optoelectronic Devices

Topics including (but are not limited to) polarization and optoacoustical devices, optical fiber gyroscopes, filters, modulators and amplifiers of optical signals, adaptive optical systems

\section{Applications (120 hs.)}

\section{Thermography}

Thermometry and thermography. Acquisition, processing, storing, visualization and interpretation of thermal images. Engineering, industrial and commercial applications.

Spectroscopy and Interferometry

Spectroscopy. Prism, grating and Fourier spectrometers. Image spectrometers. Interferometry. Michelson, FabryPerot, Mach-Zender and other types of interferometers used in communications and metrology].

Remote Sensing

Remote sensing methods and techniques. Applications in engineering, surveying and urban planning, environmental studies, assessment of natural resources and others.

Elective Application Subject

The student must select at least one Elective Subject from a menu which is presented for each teaching cycle, on the basis of having the specialists to lecture and students interested in the subject.

For the 2013-2014 cycle the list of offered courses is: 
- Applications in defense, security and surveillance

- Applications in biology and medicine

- Applications in recognition and identification of images

- Applications in optical communications systems

Seminars and Workshops (160 hs.)

The student has to attend to a mandatory Seminar on Methodology of Technological Research and optional workshops on the writing of a Thesis, and other subjects related to his/her particular Thesis field.

In this second cycle the studies conclude with a Master Thesis work with a professional-academic aim that reflects some research and development area related to optoelectronics engineering.

The work is directed by one of the faculty or an external specialist and must be defended in front of a committee of three specialists not in the Program faculty. After completion of the courses and a successful defense of the Thesis, the student receives the title of Magister en Ingeniería Optoelectrónica y Fotónica de la Universidad de Buenos Aires

It is expected that this work may be published in a regional or international refereed journal on the field.

\section{STRUCTURE OF THE COURSES}

\subsection{Redesign of contents and learning structure}

In the current syllabus the structure and contents of the subjects was redesigned in view of the experience gathered from the 2001 courses, trying to correct the difficulties and maintain the achievements of the former program. Generally speaking, the College statistics on Master programs show a number of graduates less than $10 \%$ the number of enrolled students, and in some disciplines under $1 \%$. At the same time, the graduation percentage in Specialty programs, which are less demanding in time and scope, is generally very high, in some courses achieving $100 \%$.

In our case the graduation percentage of the former program was low, and we ascertained that most enrolled students could finish and approve the subjects, but very few could even begin the Thesis work. Also, the time spent by them to complete the studies was very large in excess of the theoretical two years period.

To correct this aspect, the new program offers a one-year Speciality title and a two-year Master title, with different aims but with a common contents kernel to allow students to decide later whether they want to follow one or the other program. In this way at the end of the first year the students may have, with an additional Graduate Thesis work, a Speciality title and may end here his/her experience. On the other hand, the student may decide to continue to the second year and the Master thesis to get the Master title.

This format has been adopted in the last years in several other graduate programs trying to cope with the common situation of students that have advanced almost to the end of their Master program and cannot (or would not) complete the Thesis work. Unfortunately, these people get no recognition for their study work.

Another difficulty was the real possibility of students to assist to conventional lecture-recitations classes. In many cases family issues and an intense work load (most students are successful professionals in their fields and want to get further education to promote their careers) prevented students to take the full course schedule. Many interested professionals refrained to inscribe in the program for they have to travel frequently on work assignments, or, once having begun the program, had to abandon it as a new work position include travels and stays out of town. These problems have been addressed by including, at first in selected subjects, but with a trend to most of them, a b-learning (blended learning) approach with periodical individual and/or group meetings to achieve a continuous support via the web to the learning process. We follow also a trend to achieve a group learning system, where co-operation helps to develop competences necessary for modern engineering performance.

The new program has begun in April, 2013. All new courses are a mix of theoretical and applications contents in the blearning system. Application devoted subjects include talks by experts working in the field and visits to industrial plants and related research and development institutions. Each subject is in charge of a professional, professor of the University, who is responsible of all the teaching and evaluation tasks. 
B-learning activities includes (but is not limited to) the use of the Virtual Campus of the College (campus.fi.uba.ar), that has many resources both for teachers and students and allow virtual group meetings for discussion. Each subject is assigned a site where the teacher may leave notes, assignments (with their evaluation and comments), videos, simulations, software, question forms with automatic grading, links to related web pages, etc. Also there are discussion forums (general or particular to a subject), personal student pages with all his data and marks, group meetings, chats, etc. As a consequence of the importance of b-learning in modern graduate but also in undergraduate studies, the College of Engineering has created a special Group and Lab on Virtual Environments to help to develop this new exciting teaching and learning tools.

Anyway, there are tasks in subjects such as lab courses which have to be made in the College (or associated institutions) facilities. For this type of work an asynchronic model is proposed. The schedule is agreed with the students, trying to achieve a minimal group, to attend the lab o course work. In the other subjects, students are encouraged to use the Virtual Campus and other web resources. Besides, some work assignements and questioning can be handled through the virtual campus and considered as part of the student evaluation. An asynchronous program for the teaching tools is preferred, so the student would be free to match them to their needs, as most students are professionals with a definite agenda, and different experiences in using virtual campuses. A synchronous modality could be used for the analysis of a given particular subject, for instance by including teleconferences and/or group discussion.

At present we are beginning talks to coordinate activities with other Universities in our country, establishing agreements for using their laboratories and facilities, and carrying out joined examinations and evaluations, under the supervision of their professors, duly appointed for a given activity. For the moment being all of our students can attend presential classes and use the Virtual Campus, so there is no urgent need for this latter developments, which will be implemented as agreements are reached and facilities are at disposal.

\subsection{The Basic Structure}

\subsubsection{Laboratories}

Both the Specialty and Master students will use a dedicated Optoelectronics Laboratory, located in the main building of the College of Engineering, which is provided with an adequate infrastructure for lecturing, holding workshops and conducting different types of lab experiments in all areas of the field.

In addition, mainly for special work and the development of the Thesis, students have at their disposal the research laboratories of the GLOMAE, which comprises the Laser Laboratory, the Applied Optics Laboratory, the Electrooptics Laboratory, and the Liquid Systems Laboratory, all dependent of the Physics Department, and the Embedded Systems Laboratory and the Laboratory of Biomedical Engineering, dependent of the Electronics Department. Further research labs will de incorporated in the future. These facilities and their personnel give support to the teaching demands of the courses and the needs of research students, since in all of them a variety of devices based on optoelectronics and photonics are being used in their own research programs.

A list of the available gear includes: different types of lasers, optical benches, equipment for night vision, coherent and plain light detectors for different wavelengths, lenses, polarizers, cameras, monochromators and mirrors for the mid and near infrared and the visible spectrums, white light sources and varied electronic measuring and support equipment. All labs have also distributed computing facilities.

Both the Specialty and Master students may also have ready access to the labs and premises of other institutions as arranged through agreements, which comprises by now the National Universities of Salta, Comahue and General Sarmiento, as well as state-funded research institutions as CITEDEF, CONAE, INTI, CNEA, and private engineering companies as Telefónica de Argentina, Telecom Personal S.A, AMX Argentina, NEXTEL Communications Argentina S.A, and others to be confirmed as new agreements take place.

\subsubsection{Library resources}

The Optoelectronics Laboratory has a small dedicated library on the related fields. Books and periodicals may be consulted and used by the students.

Further support can be obtained from facilities of the Ministerio de Ciencia, Tecnología e Innovación de la Nación, through SISBI, a hub of all the universities libraries for books and periodical exchange, dedicated to easy the sharing of bibliography and periodicals publications. From IPs belonging to the University and Science System, students may also have freely available access to several engineering and scientific publishing sites such as IEEE Xplore, Springer Link, SPIE, and others. 
The Central Library of FI UBA is also available with more than 300,000 volumes, and also the smaller libraries held by the Laboratories of FI UBA which are related to the topics relevant to these graduate syllabuses.

The Central Library also has a large study hall and smaller sites with WiFi facilities are being installed in large parts of the main building of the College of Engineering.

\subsection{Members of the Graduate Faculty}

According to the stated rules in our institution, the members of the graduate faculty must be or have been regular professors (named after a public contest of proficiency), or professors directly appointed by the Ruling Council, (Consejo Directivo), as well as consulting and emeritus professors (over 65 years old). Professors of local educational institutions, other than ours may also participate, provided the institution is recognized by the Ministry of Education, and participation is always opened to Professors of qualifying foreign universities and professionals working in the field with credited experience. Members of universities must hold a Master or Doctor degree or be recognized as having equivalent background in the fields being taught.

Selection of the members is performed by the directors of both careers with the agreement of a Committee appointed by the Ruling Council. Final decision on the appointment is held by the said Ruling Council in all cases. The Ruling Council mentioned above is a democratic parliamentary like body of government of sixteen people, formed by eight professors, four graduates not necessarily involved in the School work, and four students. All are elected by the corresponding pairs.

Each course has at least one professor that supervises, teaches, and evaluates the students. To date the body of professors of the two syllabuses are recognized specialists in the subjects, and hold titles of Magister and Doctors in Physics and Engineering. Our institution has a Doctorate Program on Engineering opened to all fields of the profession. In this way we have obtained a balanced team including people from the relevant industry working on the subjects of interest, to researchers in basic in applied science related to these postgraduate studies.

Furthermore the curricular design and layout is able to support optative courses with enough flexibility, so the content of the same may be defined in accordance with the students needs, the changing world of these subjects and the availability of teachers with accredited experience to dictate them. To this aim, it is considered to invite specialists from all along the country and also from abroad, and allow for b-learning tools in intensive modes.

\section{FINAL REMARKS}

Having considered the experience obtained in the previous edition of the Optoelectronics Master Degree in FI UBA, together with the general situation of the postgraduate studies in our country, a decision was taken which consisted in dividing the studies in two subsequent yearly syllabuses. Also the number of presential class hours was diminished and the courses contents were revised and modernized for the occurring changes in the state of art. In addition optative courses have been allowed in which the characteristics are to be designed according to the needs of the students and the teaching teams.

The fact that an intermediate title is available in the studies, the provision of TICs in various formats, the introduction of thesis writing workshops within the prescribed hours of teaching, all are the introduced changes in the studies format, that will prove to be important in achieving better results, so as to avoid desertion and accomplish the learning in due time, attempting to reach a good match between the students labor life and their studying involvement in postgraduate activities.

\section{ACKNOWLEDGMENTS}

The authors want to acknowledge the support received from the College of Engineering, University of Buenos Aires which made possible the development of the Graduate Program of Optoelectronics and this presentation.

\section{REFERENCES}

[1] http://digital-library.theiet.org/content/journals/iet-opt.

[2] http://www.photonicsjournal.org/.

[3] http://www.opticseducation.org. 